\title{
PENGARUH PENYULUHAN DENGAN MEDIA ANIMASI KARTUN TERHADAP TINGKAT PENGETAHUAN TENTANG MENYIKAT GIGI PADA SISWA/I KELAS IV-B SD NEGERI 104219 TANJUNG ANOM KEC. PANCUR BATU
}

\author{
Sondang, Apri Yustika Saragih \\ Jurusan Keperawatan Gigi Poltekkes Kemenkes Medan
}

\begin{abstract}
One effort to elivate knowledge is health counseling. Counseling with various targets is more emphasized to groups of school children. The school environment is an extension of the family's hands in laying the foundation of healthy living behavior in school children. In addition, 40\% -50\% of the total population is at school children age, 6-12 years that health counseling efforts on school children's should be the foremost priority. Health counseling in schools is integrated into the school health program (UKS). This study aimed to determine the effect of counseling with cartoon animation media to the level of students' knowledge about tooth brushing among the students of grade IV-B SD Negeri 104219 Tanjung Anom, Pancur Batu Subdistrict. The research used quasi experiment method with one group pre and post test while for the statistic test, $t$-test dependent test was used. The result of $t$-Test dependent test was $p$ value $=0,00$, because $p$ $<0,05$ then Ho was rejected and Ha was accepted, meaning that this research showed that counseling with cartoon animation media had an effect to elevate knowledge about toothbrushing. It is expected that students expand their insight and knowledge about how to brush the teeth properly and correctly and maintain their dental and oral hygiene to avoid dental disease.
\end{abstract}

Keywords : Counseling, Cartoon Animation, Tooth Brushing

\section{PENDAHULUAN}

Kesehatan adalah sebagai suatu keadaan fisik, mental, sosial dan bukan hanya ketiadaan penyakit atau kelemahan (WHO, 2014).

Undang-Undang Nomor 36 Tahun 2009 tentang kesehatan menjelaskan bahwa upaya kesehatan adalah setiap kegiatan atau serangkaian kegiatan yang dilakukan secara terpadu, terintegrasi dan berkesinambungan untuk memelihara dan meningkatkan derajat kesehatan masyarakat dalam bentuk pencegahan penyakit dan pemulihan kesehatan oleh pemerintah atau masyarakat (Depkes RI, 2009).

Kesehatan merupakan bagian terpenting dalam kehidupan manusia, sehat secara jasmani dan rohani. Tidak terkecuali anak-anak, setiap orang tua menginginkan anaknya bisa tumbuh dan berkembang secara optimal, hal ini dapat dicapai jika tubuh mereka sehat. Kesehatan yang perlu diperhatikan selain kesehatan tubuh secara umum, juga kesehatan gigi dan mulut, karena kesehatan gigi dan mulut dapat mempengaruhi kesehatan tubuh secara menyeluruh (Kusumawardani, 2011).

Menurut data hasil olahan Pusat Data dan Informasi (PUSDATIN) Kementerian Kesehatan RI (2014), menunjukkan bahwa dari penduduk usia 10 tahun keatas yang menyikat gigi setiap hari hanya 2,3\% yang menyikat gigi dengan benar (sesudah sarapan dan sebelum tidur malam) pada tahun 2013 dan $7,3 \%$ pada tahun 2007.

Untuk mewujudkan derajat kesehatan yang optimal khususnya kesehatan gigi dan mulut bagi setiap orang menurut Undang-Undang Kesehatan Nomor 23 Tahun 1992 Pasal 10 dilakukan upaya kesehatan dengan pendekatan pemeliharaan, promotif, preventif, kuratif dan rehabilitatif yang dihasilkan secara menyeluruh, terpadu dan berkesinambungan.

Pengetahuan (knowledge) merupakan hasil dari tahu, yang terjadi setelah orang melakukan pengindraan terhadap suatu objek tertentu. Penginderaan terjadi melalui pancaindera, yakni : indera penglihatan, pendengaran, penciuman, rasa dan raba. Sebagian besar pengetahuan manusia diperoleh mata dan telinga (Notoadmodjo, 2010).

Upaya untuk meningkatkan pengetahuan adalah dengan penyuluhan kesehatan. Penyuluhan dengan berbagai sasaran lebih ditekankan pada kelompok rentan anak sekolah. Lingkungan sekolah merupakan perpanjangan tangan keluarga dalam meletakkan dasar perilaku hidup sehat bagi anak sekolah. Disamping itu, jumlah populasi anak sekolah umur 6-12 tahun mencapai $40 \%-50 \%$ dari komunitas umum, sehingga upaya penyuluhan kesehatan pada sasaran anak sekolah 
merupakan prioritas pertama dan utama (Notoadmodjo, 2005).

Menurut Notoadmodjo (2003) bahwa seseorang dapat mempelajari sesuatu dengan lebih baik apabila menggunakan lebih dari satu indera ketika menerima penyuluhan, apa yang diingat dari isi penyuluhan adalah 50\% dari apa yang didengar dan dilihat. Semakin banyak menggunakan penginderaan dalam belajar maka akan semakin baik, panca indera yang paling banyak menyalurkan pengetahuan ke otak adalah mata (kurang lebih sampai $87 \%$ ), sedangkan $13 \%$ pengetahuan manusia diperoleh atau disalurkan melalu indera lainnya (Depkes RI, 2008).

Media Penyuluhan merupakan upaya yang dapat digunakan untuk menyalurkan pesan dari pengirim pesan ke penerima sehingga dapat merangsang pikiran, perasaan, perhatian dan minat dalam memelihara kesehatan secara optimal (Sebaris, 2016).

Animasi merupakan suatu tekhnik dalam pembuatan karya audio visual yang berdasarkan terhadap pengaturan waktu dan gambar. Gambar yang telah dirangkai dari beberapa potongan gambar yang bergerak sehingga terlihat menarik dan dapat menghadirkan daya tarik bagi siswa.

Kartun adalah salah satu jenis media grafis yang digunakan dalam dunia pendidikan berfungsi sebagai alat memperjelas materi, menciptakan nilai rasa lebih dalam memahami materi, sebagai media kritisi dan sebagainya (Sulton, 2009).

Berdasarkan hasil survey awal yang dilakukan pada 10 orang siswa/i SD Negeri 104219 Tanjung Anom Kec. Pancur Batu ditemukan pengetahuan siswa/i tentang kesehatan gigi dan mulut masih kurang dan dari data yang diperoleh dari sekolah bahwa belum pernah dilakukan upaya kesehatan gigi dan mulut berupa promotif, preventif dan kuratif.

\section{Tujuan Penelitian}

Untuk mengetahui pengaruh penyuluhan dengan media animasi kartun terhadap tingkat pengetahuan tentang menyikat gigi pada siswa/i kelas IV-B SD Negeri 104219 Tanjung Anom Kec. Pancur Batu.

\section{Manfaat Penelitian}

Hasil penelitian ini diharapkan dapat :

1. Menambah wawasan dan pengetahuan tentang menyikat gigi siswa/i khususnya kelas IV-B SD Negeri 104219 Tanjung Anom Kec. Pancur Batu.

2. Menambah wawasan bagi penulis dan pembaca tentang pengaruh penyuluhan dengan media animasi kartun terhadap pengetahuan tentang menyikat gigi.

3. Sebagai bahan referensi bagi peneliti selanjutnya di perpustakaan Poltekkes Kemenkes RI Medan.

\section{METODE PENELITIAN}

\section{Jenis dan Desain Penelitian}

Jenis penelitian yang digunakan adalah penelitian analitik dengan metode Quasi Eksperiment (eksperimen semu) dan rancangan one group pre-post test design yaitu suatu penelitian dengan adanya suatu perlakuan terhadap kelompok sampel tetapi tidak ada kelompok kontrol. berikut :

Bentuk rancangan penelitian ini adalah sebagai

\begin{tabular}{|c|c|c|}
\hline Pre-test & Perlakuan & Post-test \\
\hline 01 & $\mathrm{X}$ & 02 \\
\hline
\end{tabular}

Keterangan :

$01=$ Tingkat pengetahuan responden tentang menyikat gigi sebelum dilakukan penyuluhan dengan media animasi kartun

$\mathrm{X}=$ Perlakuan berupa penyuluhan dengan media animasi kartun

02 = Tingkat Pengetahuan responden tentang menyikat gigi sesudah dilakukan penyuluhan dengan media animasi kartun

\section{Populasi dan Sampel \\ Populasi}

Populasi adalah keseluruhan objek penelitian atau objek yang diteliti (Notoatmodjo, 2010). Adapun populasi yang akan diteliti adalah siswa/i kelas IV-B SD Negeri 104219 Tanjung Anom Kec. Pancur Batu sebanyak 30 orang.

\section{Sampel}

Sampel adalah sebagian yang diambil dari keseluruhan objek yang diteliti dan dianggap mewakili populasi (Notoadmodjo, 2010). Apabila jumlah populasi kurang dari 100, maka sampel populasi dijadikan sampel penelitian seluruhnya (Sugiyono, 2007). Maka sampel yang diambil adalah siswa/i kelas IV-B SD Negeri 104219 Tanjung Anom Kec. Pancur Batu berjumlah 30 orang dengan teknik total sampling.

\section{HASIL DAN PEMBAHASAN}

\section{Hasil Penelitian}

Data yang dikumpulkan adalah hasil penelitian yang dilakukan terhadap siswa/i kelas IV-B SD Negeri 104219 Tanjung Anom Kec. Pancur Batu.

\section{Analisa Univariat}

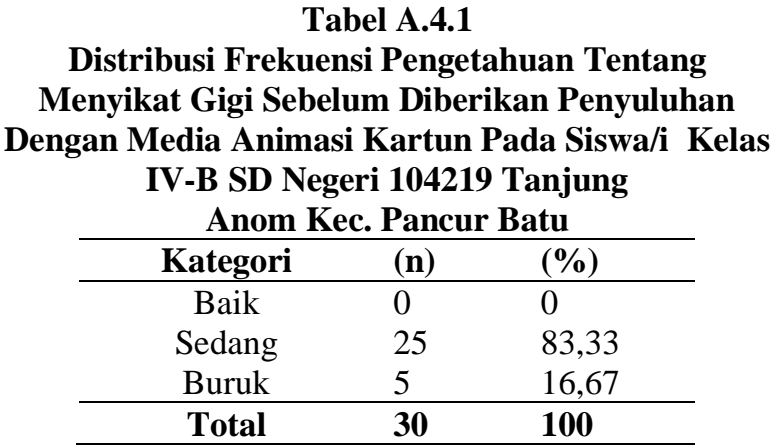

Dari tabel A.4.1 diatas dapat kita ketahui bahwa tingkat pengetahuan siswa/i sebelum diberikan penyuluhan dengan media animasi kartun yaitu tidak ada siswa dengan kategori baik $(0 \%), 25$ siswa dengan 
kategori sedang $(83,33 \%)$ dan 5 siswa dengan kategori buruk $(16,67 \%)$.

Tabel A.4.2

Distribusi Frekuensi Pengetahuan Tentang Menyikat Gigi Sesudah Diberikan Penyuluhan Dengan Media Animasi Kartun Pada Siswa/i Kelas IV-B SD Negeri 104219 Tanjung Anom Kec. Pancur Batu

\begin{tabular}{cll}
\hline Kategori & $(\mathbf{n})$ & $(\mathbf{\%})$ \\
\hline Baik & 27 & 90 \\
Sedang & 3 & 10 \\
Buruk & 0 & 0 \\
\hline Total & $\mathbf{3 0}$ & $\mathbf{1 0 0}$ \\
\hline
\end{tabular}

Dari tabel A.4.2 diatas dapat kita ketahui bahwa tingkat pengetahuan siswa/i setelah diberikan penyuluhan dengan media animasi kartun yaitu 27 siswa dengan kategori baik (90\%), 3 siswa dengan kategori sedang $(10 \%)$ dan tidak ada siswa dengan kategori buruk $(0 \%)$.

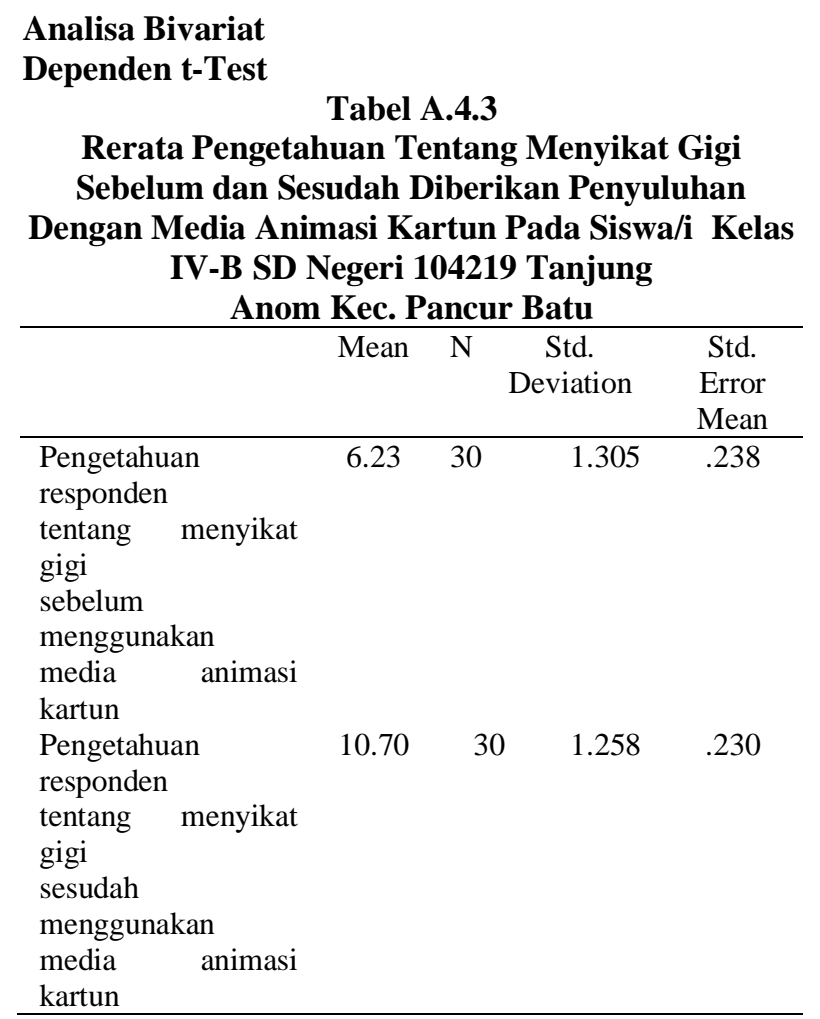

Dari tabel 4.3 diatas dapat diketahui bahwa tingkat pengetahuan responden tentang menyikat gigi sebelum menggunakan media animasi kartun memiliki rata-rata skor 6,23 sedangkan tingkat pengetahuan responden tentang menyikat gigi sesudah menggunakan media animasi kartun memiliki rata-rata 10,73.

Berdasarkan dari tabel 4.3 tersebut dapat diketahui bahwa tingkat pengetahuan siswa/i tentang menyikat gigi setelah penyuluhan dengan media animasi kartun mengalami peningkatan dari kategori sedang menjadi kategori baik.

\section{Uji Hipotesis}

Dalam penelitian ini hipotesis yang diajukan adalah hipotesis alternatif, yaitu antara hipotesis nol $\left(\mathrm{H}_{0}\right)$ dan hipotesis alternatif $\left(\mathrm{H}_{\mathrm{a}}\right)$, ditetapkan sebagai berikut :

$\mathrm{H}_{0}$ : Tidak ada pengaruh penyuluhan dengan media animasi kartun terhadap tingkat pengetahuan siswa/i tentang menyikat gigi.

$\mathrm{H}_{\mathrm{a}}$ : Ada pengaruh penyuluhan dengan media animasi kartun terhadap tingkat pengetahuan siswa/i tentang menyikat gigi.

Uji hipotesis dinyatakan bermakna bila $p \leq 0,05$ pada tingkat kepercayaan $95 \%$.

Untuk membuktikan hipotesis tersebut maka dilakukan uji statistik dengan menggunakan uji paired samples test sebagai berikut :

Tabel 4.4

Paired Sampel Test Pengaruh Penyuluhan Dengan Media Animasi Kartun Terhadap Tingkat

Pengetahuan Tentang Menyikat Gigi Pada Siswa/i Kelas IV-B SD Negeri 104219 Tanjung Anom Kec. Pancur Batu

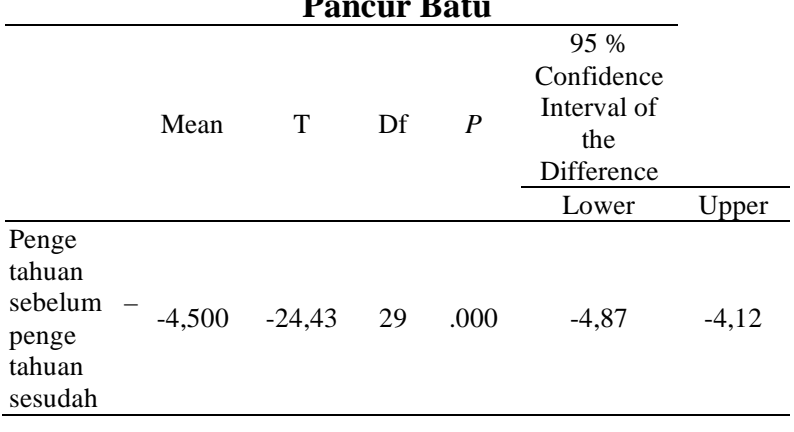

Dari hasil uji statistik diatas diperoleh $p$ value $($ Sig. $(2$-tailed $))=0,000$, maka diambil kesimpulan, yaitu :

Berdasarkan nilai probabilitas :

- Jika probabilitas $>0,05 \rightarrow \mathrm{H}_{0}$ diterima

- Jika probabilitas $<0,05 \quad \rightarrow \mathrm{H}_{0}$ ditolak

Dari tabel diatas diketahui bahwa probabilitas adalah 0,000. Oleh karena probabilitas $<0,05$, maka $\mathrm{H}_{0}$ ditolak.

Berdasarkan data statistik tersebut maka dapat disimpulkan bahwa ada pengaruh penyuluhan dengan media animasi kartun terhadap tingkat pengetahuan tentang menyikat gigi pada siswa/i kelas IV-B SD Negeri 104219 Tanjung Anom Kec. Pancur Batu.

\section{Pembahasan}

Penyuluhan adalah kegiatan yang dilakukan dengan menyebarkan pesan, menanamkan keyakinan sehingga masyarakat tidak saja sadar, tahu, dan mengerti, tetapi juga mau dan dapat melakukan anjuran yang berhubungan dengan kesehatan (Azwar, 2010). Penyuluhan sangat berperan penting terhadap peningkatan pengetahuan karena didalam penyuluhan sasaran memperoleh pendidikan dan pengetahuan tentang kesehatan yang lebih baik.

Pengetahuan (knowledge) merupakan hasil dari tahu, yang terjadi setelah orang melakukan pengindraan 
terhadap suatu objek tertentu. Pengindraan terjadi melalui pancaindra, yakni : indra penglihatan, pendengaran, penciuman, rasa dan raba. Sebagian besar pengetahuan manusia diperoleh mata dan telinga (Notoadmodjo, 2010).

Untuk memaksimalkan pemanfaatan indera sasaran diperlukan alat bantu penyuluhan yang ditentukan oleh tujuan penyuluhan karena setiap alat bantu memiliki intensitas yang berbeda. Jika tujuan penyuluhan pada aspek pengertian/pengetahuan maka pesan yang disampaikan cukup dengan lisan namun harus menggunakan alat peraga yang dapat menarik minat sasaran penyuluhan. Salah satunya adalah media animasi termasuk jenis media audio visual karena lebih dominan pada gerak dan suara (Maulana, 2009). Keunggulan animasi adalah kemampuannya untuk menjelaskan suatu kejadian secara sistematis dalam tiap perubahan. Hal ini sangat membantu dalam menjelaskan prosedur dan urutan kejadian (Suheri, 2006). Serta kemampuannya besar sekali untuk menarik perhatian, mempengaruhi sikap maupun tingkah laku. Kalau animasi mengena, pesan yang besar bisa disajikan secara ringkas dan kesannya akan tahan lama diingatan (Sadiman, 2009). Sehingga, penyuluhan dengan media animasi sangat berpengaruh dalam meningkatkan pengetahuan siswa/i tentang menyikat gigi.

Adapun, kelebihan media animasi kartun yang digunakan sebagai media penyuluhan diantaranya adalah :

1. Memotivasi siwa/i untuk meningkatkan perhatian karena menghadirkan daya tarik.

2. Dapat memperjelas apa yang ditayangkan dan lebih mudah ditangkap serta diingat karena media animasi yang dilengkapi suara dan gambar.

3. Dapat memberi dorongan yang kuat bagi siswa/i untuk meningkatkan pengetahuan sesuai dengan pesan yang disampaikan.

\section{SIMPULAN DAN SARAN}

\section{Simpulan}

Berdasarkan hasil penelitian yang telah dilakukan mengenai pengaruh penyuluhan dengan media animasi kartun terhadap pengetahuan tentang menyikat gigi pada siswa/i kelas IV-B SD Negeri 104219 Tanjung Anom Kec. Pancur Batu, maka diperoleh kesimpulan bahwa :

1. Tingkat pengetahuan siswa/i sebelum diberikan penyuluhan dengan media animasi kartun yaitu tidak ada siswa dengan kategori baik $(0 \%), 25$ siswa dengan kategori sedang $(83,33 \%)$ dan 5 siswa dengan kategori buruk $(16,67 \%)$. Sedangkan, tingkat pengetahuan siswa/i sesudah diberikan penyuluhan yaitu 27 siswa dengan kategori baik (90\%), 3 siswa dengan kategori sedang (10\%) dan tidak ada siswa dengan kategori buruk $(0 \%)$.

2. Hasil uji statistik dengan menggunakan uji t-Test dependent menunjukkan bahwa diperoleh hasil nilai $\mathrm{p}=0,00$, karena $\mathrm{p}<0,05$ maka $\mathrm{H}_{0}$ ditolak dan $\mathrm{H}_{\mathrm{a}}$ diterima, yang berarti bahwa ada pengaruh penyuluhan dengan media animasi kartun terhadap tingkat pengetahuan tentang menyikat gigi.

\section{Saran}

Sesuai dengan hasil penelitian yang telah diperoleh, maka diharapkan :

1. Penyuluhan tentang kesehatan gigi dan mulut anak dapat lebih ditingkatkan melalui program UKGS kepada siswa/i terutama dengan menggunakan media animasi kartun.

2. Diharapkan kepada siswa/i kelas IV-B SD Negeri 104219 Tanjung Anom Kec. Pancur Batu dapat menambah wawasan dan ilmu pengetahuan tentang cara menyikat gigi yang baik dan benar serta dalam menjaga kebersihan gigi dan mulut agar terhindar dari penyakit gigi.

3. Kepada orangtua murid agar dapat memberikan perhatian lebih terutama dalam hal menjaga kebersihan gigi dan mulut anaknya serta membimbing anak tentang cara menyikat gigi yang baik dan benar.

\section{DAFTAR PUSTAKA}

Arikunto, S., 2010, Prosedur Penelitian Suatu Pendekatan Praktik, Jakarta : Rineka Cipta.

Azwar, S., 2010, Sikap Manusia Teori dan Pengukurannya, Yogyakarta : Pustaka Pelajar.

Herijulianti, E., 2011, Ilmu Pencegahan Penyakit Jaringan Keras dan Jaringan Pendukung Gigi, Jakarta : EGC.

Hidayat, R dkk., 2016, Kesehatan Gigi dan Mulut ; Apa Yang Sebaiknya Anda Tahu?, Yogyakarta : Andy Offset.

Kusumawardani, Endah., 2011, Buruknya Kesehatan Gigi dan Mulut, Yogyakarta : Hanggar Keraton.

Maulana, Heri., 2009, Promosi Kesehatan, Jakarta : EGC.

Noor, Juliansyah., 2011, Metodologi Penelitian, Jakarta : Prenada Media Group.

Notoadmodjo, Soekidjo., 2003, Metodologi Penelitian Kesehatan, Jakarta : Rineka Cipta.

Jakarta : Rineka Cipta.

Pintauli, S dkk., 2016, Menuju Gigi dan Mulut Sehat ; Pencegahan dan Pemeliharaannya. Medan : USU Press.

Rachmat, H., 2016, Kesehatan Gigi dan Mulut, Yogyakarta : CV Andi Offset.

Sadiman A. S., 2009, Media Pendidikan (Pengertian, Pengembangan dan Pemanfaatannya), Jakarta : Rajawali Pers.

Sebaris, H., 2016, Promosi Kesehatan : Pemberdayaan Masyarakat, dan Sosial Yogyakarta : Nuha Mediak.

Sugiyono., 2009, Metode Penelitian Kuantitatif \& Kualitatif, Bandung : Alfabeta.

https://muhammadiqbalm.wordpress.com/2012/08/08/p engertian-media/ diakses tanggal 2 Maret 2018 